\title{
Simple approach to histological diagnosis of common skin adnexal tumors
}

This article was published in the following Dove Press journal:

Pathology and Laboratory Medicine International

17 July 2017

Number of times this article has been viewed

\author{
Ahmed A Alhumidi \\ Department of Pathology, College \\ of Medicine, King Saud University, \\ Riyadh, Saudi Arabia
}

Correspondence: Ahmed A Alhumidi Department of Pathology, College of Medicine, King Saud University, PO Box 2925, Riyadh II 46I, Saudi Arabia Email ahmedbgj@hotmail.com

\begin{abstract}
Most adnexal neoplasms are uncommonly encountered in routine practice, and pathologists can recognize a limited number of frequently encountered tumors. In this review, I provide a simplified histological approach to be used by general pathologists and residents of pathology and dermatology programs. These tumors are classified into 1) tumors connected to epidermis, 2) tumors not connected to epidermis, 3) sebaceous tumors, and 4) dermal cysts.

Keywords: skin, adnexal tumors, histology, approach
\end{abstract}

\section{Introduction}

Tumors of the skin appendages have been classified into four groups that exhibit histologic features analogous to hair follicles, sebaceous glands, apocrine glands, and eccrine glands (Figure 1). Most adnexal neoplasms are relatively uncommonly encountered in routine practice, and pathologists can recognize a limited number of frequently encountered tumors. In this article, I reviewed the histological features of the common skin adnexal tumors with an emphasis on simple diagnostic histological approach. This approach depends generally on the location of the tumor, cell cytoplasm and color of the tumor in a low power. Some tumors are located superficially and predominantly connect to epidermis and others lie deep in the dermis. Peripheral palisading, keratinous cyst, papillary mesenchymal bodies (primitive hair papilla formation), trichohyaline granules, and ghost cells are features associated with hair follicle differentiation. Vacuolated cytoplasm indicates sebaceous differentiation. Tubular and glandular structures are seen in sweat gland tumors. Apical snouts or decapitation secretion indicates apocrine origin. Clear cells can be seen in hair follicle tumors (e.g., trichilemmoma [TL]) and sweat gland tumors (e.g., clear cell hidradenoma) and should not be misinterpreted as vacuolated cells of sebaceous tumors.

\section{Review}

\section{Tumors predominantly with epidermal connection}

Poroma, trichilimmoma, Syringocystadenoma papilliferum with their malignant counterparts are tumors that predominantly attach to epidermis. Tumors with dilated pore are included in this section because of their epidermal connection

Epidermal connection + basaloid (blue) tumor + cuticle formation $=$ poroma and porocarcinoma

Poroma is a benign adnexal neoplasm with terminal ductal differentiation. Although historically considered a neoplasm of eccrine differentiation, poromas can show either 


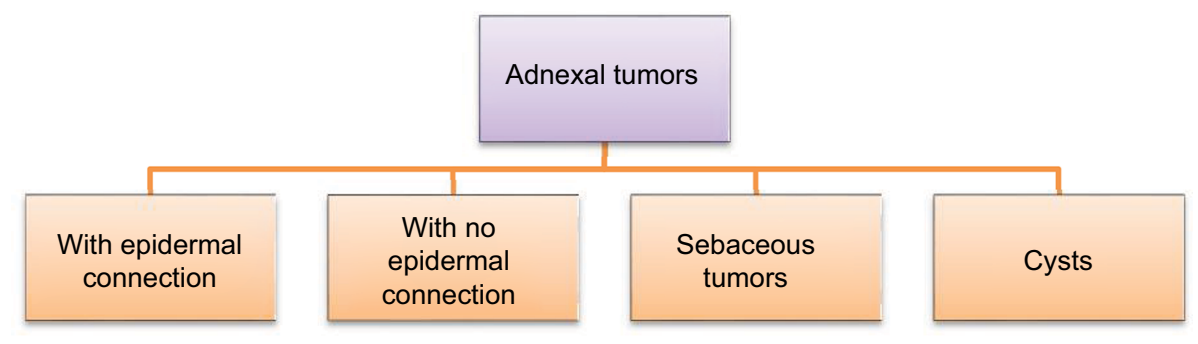

Figure I General approach to adnexal tumors.

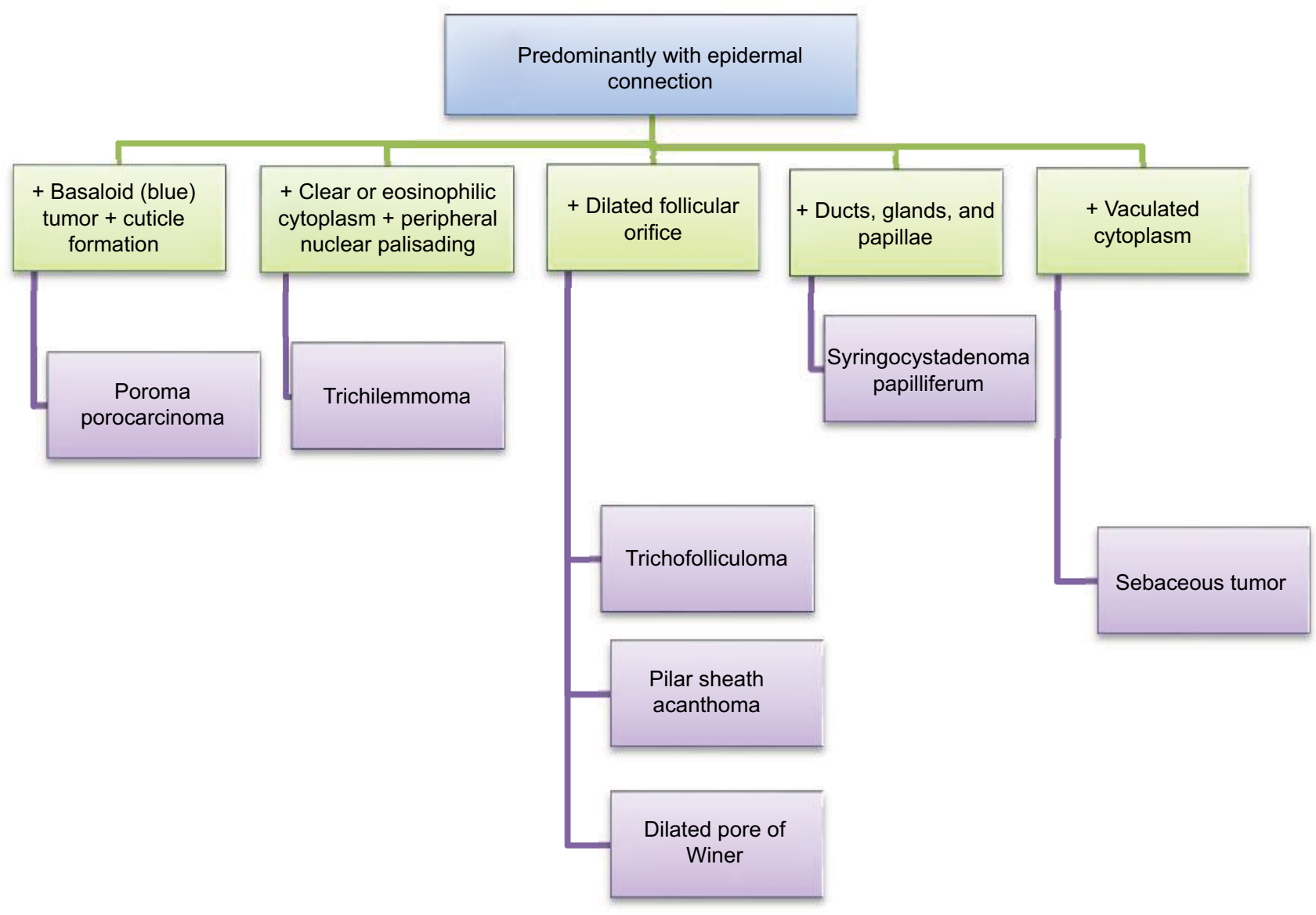

Figure 2 Tumors that predominantly connect to epidermis.

eccrine or apocrine lineage. Histologically, poroma arises within the lower portion of the epidermis, from where it emanates downward into the dermis as tumor masses that often consist of broad, anastomosing bands of epithelial cells punctuated by focal ducts and occasional cysts. The stroma surrounding poromas is often richly vascular (Figures 2 and $3 \mathrm{~A}, \mathrm{~B})$. Architecturally, this tumor shows a spectrum of change from predominately intraepidermal lesions (hidroacanthoma simplex) to primarily dermal-based neoplasms (dermal duct tumor). ${ }^{1}$

Porocarcinomas are usually found on the lower extremities. They are associated with an eccrine poroma and are histologically characterized by asymmetrical, solid, nodular growth pattern, with infiltrative borders. The neoplastic cells show varying degrees of nuclear atypia and necrosis. ${ }^{2}$

Epidermal connection + clear or eosinophilic cytoplasm + peripheral nuclear palisading $=$ Trichilemmoma (TC) and tumor of follicular infundibulum

TL is a benign tumor that arises from the outer root sheath of the hair follicle occurring frequently on the face of adults. Multiple facial TLs are specifically associated with Cowdens disease. ${ }^{3}$ Most cases of TL present as a sharply circumscribed superficial exo-endophytic proliferation with a papillated surface. The dominating histological pattern of TL is that of one 
or several lobules that are seen descending from the surface epidermis into the dermis. A variable number of tumor cells have the appearance of clear cells because of their content of glycogen (Figure 3C). At the periphery, pale columnar cells are arranged in a palisade, bordered by PAS-positive basement membrane. Desmoplastic trichilemmoma is a variant of TL-characterized irregular extensions of cells of the outer root sheath type that project into sclerotic collagen bundles and mimic invasive carcinoma. Unlike carcinomas, desmoplastic TLs stain with CD34. ${ }^{1,4}$

Tumor of the follicular infundibulum usually occurs as a solitary, flat, keratotic papule on the face. Histologically, it is composed of plate-like growth of anastamosing epithelial cells connected to the overlying epidermis with peripheral nuclear palisading. The centrally located cells show clear cytoplasm that contain glycogen material. ${ }^{1}$

$$
\begin{aligned}
& \text { Epidermal connection }+ \text { dilated orifice }=\text { trichofolliculoma, } \\
& \text { pilar sheath acanthoma, and dilated pore of Winer }
\end{aligned}
$$

Trichofolliculoma (TF) occurs in adults as a solitary lesion, usually on the face but occasionally on the scalp or neck. TF is a symmetrical, well-circumscribed, vertically oriented lesion composed of three components: infundibulocystic, follicular, and stromal. Low-power microscopic examination shows keratin-filled cyst lined by squamous epithelium associated with secondary hair follicles (Figures 4A and B). Differential diagnosis of TF includes pilar sheath acanthoma. Histologically, it has a superficial broad invagination of cells, which often have eosinophilic or clear (glycogenated) cytoplasm, producing a crater-like cavity (Figure 4C). Dilated pore of Winer shows invagination of the surface epithelium, lined by relatively thin stratified squamous epithelium and lacking the hair follicles (Figure 4D). In trichodiscoma/fibrofolliculoma, the lesion is characterized by dilated cyst, from which there is proliferation of thin, trabeculated strands of basophilic epithelium within a prominent fibrous stroma. Multiple lesions are seen in Birt-Hogg-Dubé syndrome, which is an autosomal dominant condition and is associated with benign and malignant renal neoplasms, lung cysts, and spontaneous pneumothorax. ${ }^{5}$

$$
\begin{aligned}
& \text { Epidermal connection }+ \text { ducts, glands, and papillae }=\text { syrin- } \\
& \text { gocystadenoma papilliferum }
\end{aligned}
$$

Syringocystadenoma papilliferum is a benign adnexal neoplasm that occurs predominantly in scalp and is associated with nevus sebaceous in at least one-third of cases. Histologically, one or several cystic invaginations extend downward from
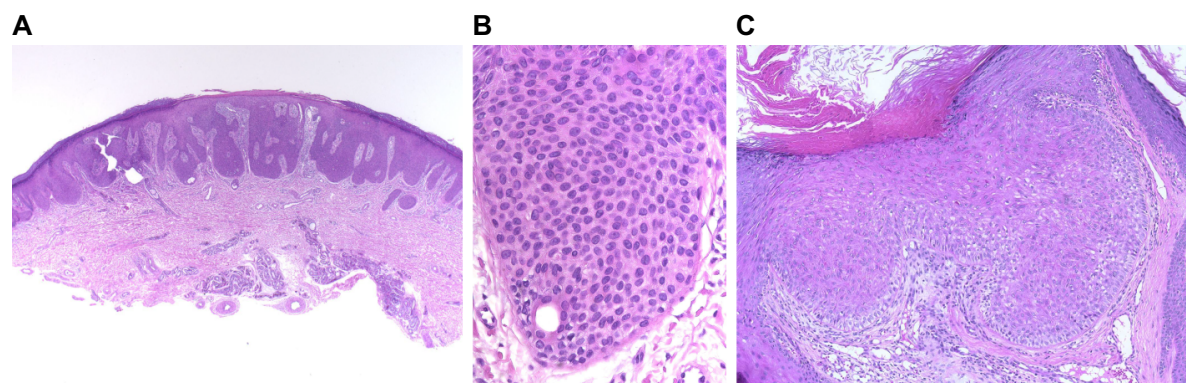

Figure 3 Predominantly epidermal tumors with basophilic, eosinophilic or clear cytoplasms.

Notes: (A) Poroma: basaloid tumor that is primarily connected to epidermis (H\&E stain original magnification $\times 20$ ). (B) Poroma: on a high power, small cuticle (ductile) can be seen (H\&E stain original magnification $\times 400)$. (C) TL: eosinophilic tumor connected to overlying epidermis with peripheral nuclear palisading (magnification $\times 200)$. Abbreviations: H\&E, hematoxylin and eosin; TL, trichilemmoma.

A

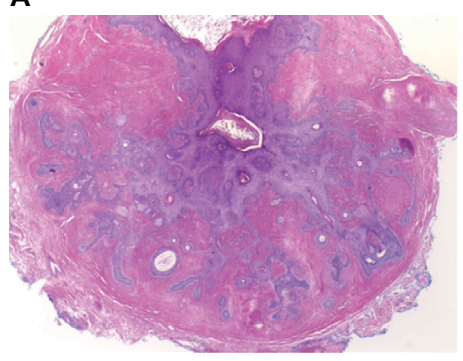

B

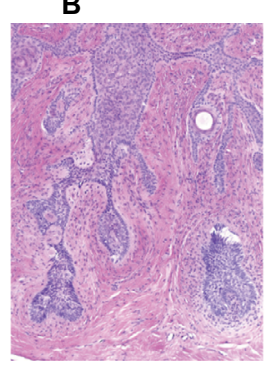

C

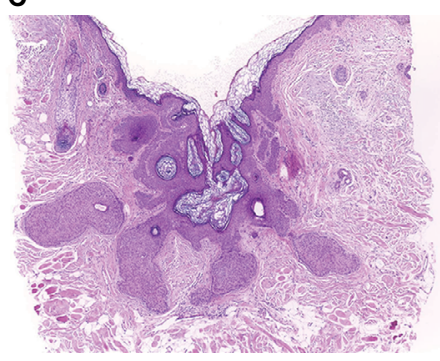

D

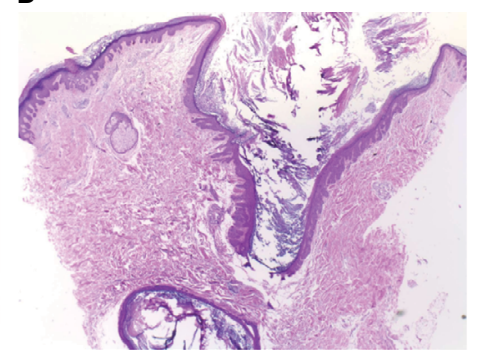

Figure 4 Tumors with dilated pore.

Notes: (A) TF: dilated pore that is primarily connected to epidermis (H\&E stain original magnification $\times 20$ ). (B) TF: from the epithelial walls, smaller infundibula radiate, to which are attached vellus follicles in various numbers (H\&E stain original magnification $\times 200$ ). (C) Pilar sheath acanthoma: dilated pore that is primarily connected to epidermis (H\&E stain original magnification $\times 20$ ). (D) Dilated pore that is primarily connected to epidermis from which rete ridges are connected (H\&E stain original magnification $\times 40$ ). Abbreviations: TF, trichofolliculoma; H\&E, hematoxylin and eosin. 
the epidermis forming small cystic areas lined by double layer of epithelial and myoepithelial cells with evidence of decapitation (apical snout) secretion (Figure 5). Plasma cells are consistently numerous within the stroma. ${ }^{1}$ Syringocystadenocarcinoma papilliferum is very rare and is characterized histologically by disorderly arrangement of papillary projections, cytological atypia and loss of double-layered epithelium. ${ }^{6}$

\section{Tumors with no epidermal connection}

Most of the adnexal tumors are predominantly dermal and many of them may show minimal epidermal connection. These are divided into basaloid, clear or eosinophilic and tumors with glandular differentiation.

No epidermal connection + basaloid tumor + peripheral nuclear palisading $=$ trichoepithelioma and trichoblastoma

Trichoepithelioma is a benign tumor that can occur as a sporadic, solitary lesion or an autosomal dominant familial disorder known as Brooke-Spiegler syndrome. Histologically, it is a well-circumscribed and symmetric lesion that predominantly consists of uniform basaloid cells with peripheral palisading, surrounded by dense stroma that contains fibroblasts forming papillary mesenchymal bodies. In contrast with basal cell carcinoma (BCC), artefactual stroma and myxoid stroma are not present (Figures 6 and 7). Immunohistochemically, trichoepithelioma expresses scattered Merkel cell cytokeratin 20 positivity, while $\mathrm{BCC}$ is positive for androgen receptor (AR). ${ }^{7}$ Trichoadenoma is a rare benign follicular neoplasm characterized by proliferation keratin cysts with rare germinal basaloid cells. Desmoplastic trichoepithelioma (DTE) is characterized by narrow, compressed strands of basaloid germinative epithelium, embedded in densely sclerotic stroma within the upper dermis. It is important to differentiate DTE from morphea-like BCC. CK 20 may identify occasional Merkel cells within DTE, which are absent in BCC. ${ }^{7}$
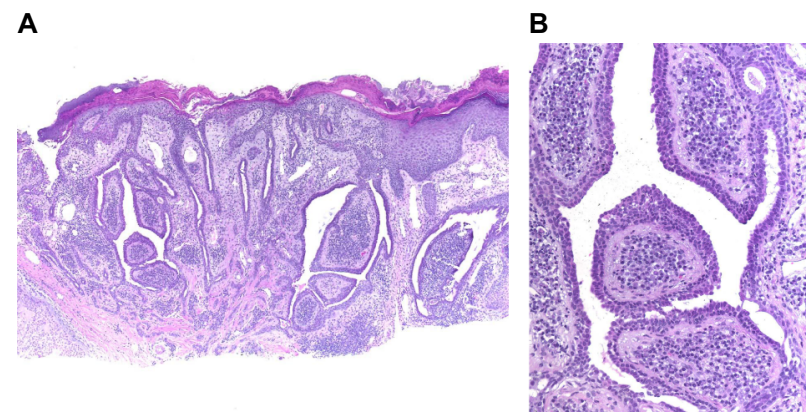

Figure 5 Epidermal tumor with glandular differentiation.

Notes: (A) Syringocystadenoma papilliferum: a tumor that is primarily connected to epidermis (H\&E stain original magnification $\times 40$ ). (B) Syringocystadenoma papilliferum: the tumor is composed of glands and ducts with apocrine differentiation (H\&E stain original magnification $\times 200$ ).

Abbreviation: H\&E, hematoxylin and eosin.

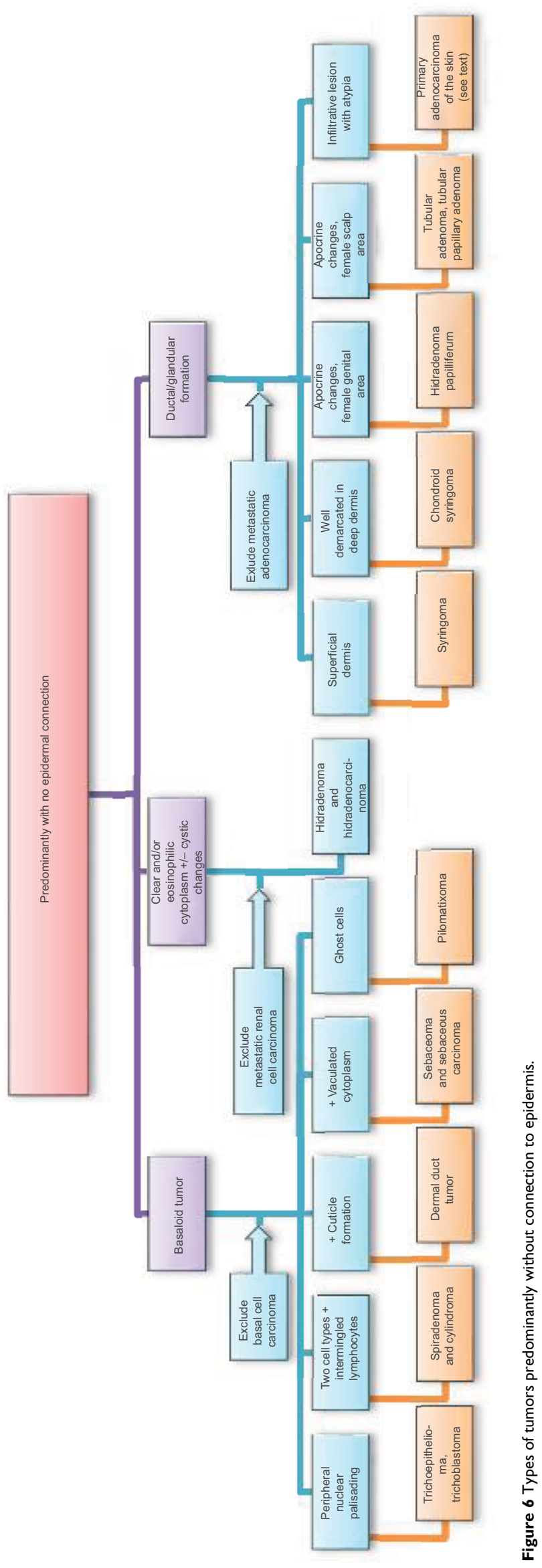


A

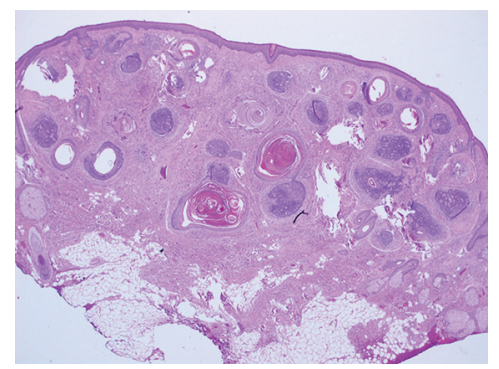

D

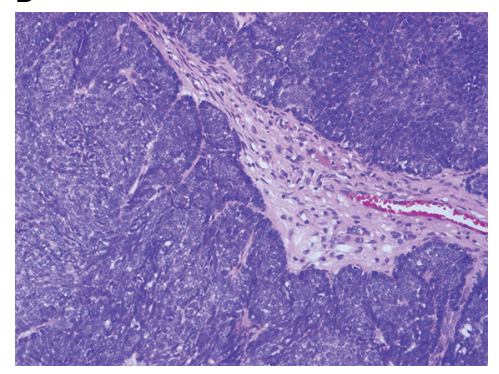

G

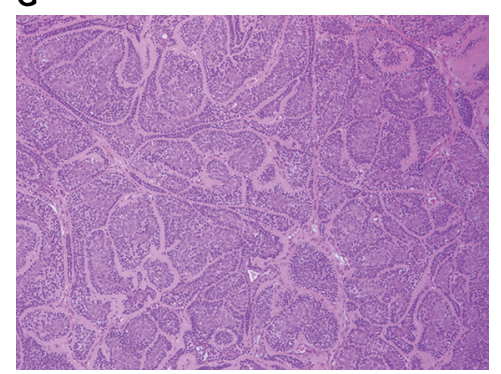

B

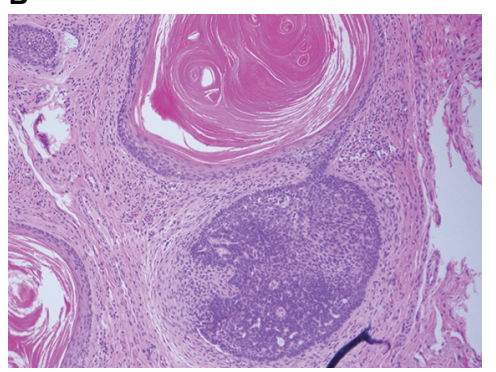

E

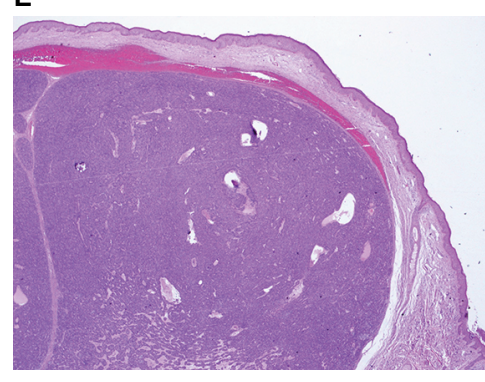

H

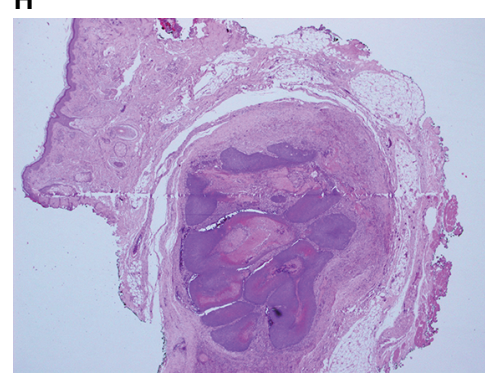

C

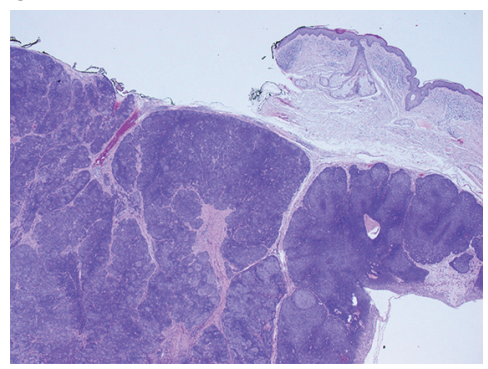

$\mathbf{F}$

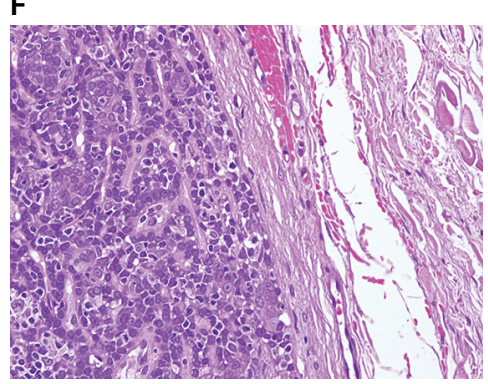

I

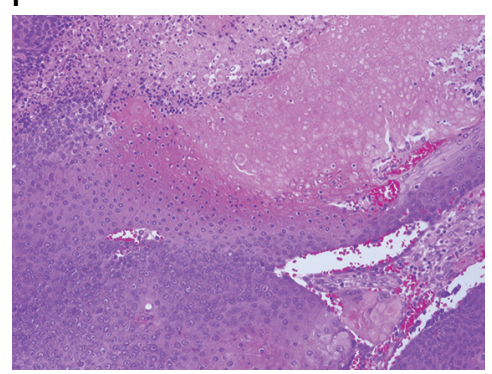

Figure 7 Predominantly dermal tumors with basaloid appearance.

Notes: (A) Trichoepithelioma: basaloid dermal lobules with small keratinous cysts (H\&E stain original magnification $\times 20)$. (B) Trichoepithelioma: on a high power, peripheral nuclear palisading and papillary mesenchymal body are appreciated (H\&E stain original magnification $\times 200)$. (C) Trichoblastoma: tumor is composed of predominantly blue dermal lobules (H\&E stain original magnification $\times 20$ ). (D) Trichoblastoma: on a high power, peripheral nuclear palisading without papillary mesenchymal bodies or keratinous cysts $(H \& E$ stain original magnification $\times 200)$. (E) Spiradenoma: tumor is composed of predominantly blue dermal lobule $(H \& E$ stain original magnification $\times 20)$. $(\mathbf{F})$ Spiradenoma: on a high power, two distinct populations of neoplastic epithelial cells can be seen, dark and pale with scattered lymphocytes (H\&E stain original magnification $\times 200$ ). (G) Cylindroma: differ from spiradenoma only by its low power appearance of jigsaw puzzle (H\&E stain original magnification $\times 40)$. (H) Pilomatrixoma: tumor is composed of eosinophilic and blue components (H\&E stain original magnification $\times 20$ ). (I) Pilomatrixoma: on a high power, two populations of cells can be seen, dark blue and eosinophilic shadow cells (H\&E stain original magnification $\times 200$ ).

Abbreviation: H\&E, hematoxylin and eosin.

Trichoblastoma is a benign neoplasm differentiated toward the trichoblast. Histologically, it is a large, circumscribed basaloid tumor that shows less follicular differentiation than trichoepithelioma (Figure 7C). ${ }^{1}$ Merkel cells, identified by CK 20 , are frequently seen in trichoblastoma compared with BCC. ${ }^{7}$ Cutaneous lymphadenoma is a rare variant of trichoblastoma that is composed of multiple rounded lobules of basaloid cells with peripheral palisading and infiltrate of small mature lymphocytes. ${ }^{1}$

No epidermal connection + basaloid tumor + two cell types

+ intermingled lymphocytes $=$ spiradenoma and cylindroma

Spiradenoma is a benign dermal neoplasm that can show either eccrine or apocrine differentiation. Pain is one of the main clinical characteristics of spiradenoma. It can rarely be associated with Brooke-Spiegler syndrome. Microscopically, the tumor consists of one large, sharply demarcated lobule, but more commonly there are several lobules located in the dermis without connections to the epidermis. At a higher magnification, two distinct populations of neoplastic epithelial cells can be seen: cells with small, dark nuclei (located at the periphery of the cellular aggregates) and the other type of cells with large, pale nuclei (located in the center of the aggregates). T-lymphocytes are usually identified within the tumor (Figures 7E, F). ${ }^{8}$ Spiradenoma and cylindroma are closely related, probably representing two morphologic expressions of the same basic neoplastic process. ${ }^{1}$ Cylindroma differs in its low-power appearance of jigsaw puzzle (Figure 7G). The nests of cylindroma are commonly surrounded by a rim of densely eosinophilic PAS-positive basement membrane 
material. High power shows same cytological features of spiradenoma. Spiradenocarcinoma is a malignant adnexal neoplasm resulting from malignant transformation of a benign spiradenoma. In all cases, there are recognizable areas of a benign spiradenoma. The malignant part shows loss of nodular growth pattern, infiltrative borders, nuclear atypia, and tumor necrosis. ${ }^{9}$

No epidermal connection + basaloid tumor + ghost cells $=$ pilomatrixoma

Pilomatrixoma (pilomatricoma, calcifying epithelioma of Malherbe) is a benign lesion with differentiation toward the matrix of the hair follicle. Histopathologically, the appearance varies according to the age of the lesion. There are two basic cell types, basophilic cells and eosinophilic shadow cells. These shadow (mummified) cells form from the basophilic cells, and the transition may be relatively abrupt or may take place over several layers of cells (transitional cells) (Figures 7H, I). Pilomatrix carcinoma is the malignant counterpart of pilomatricoma. Histologically, it differs from pilomatricoma in asymmetrical growth pattern, poor circumscription, and significant nuclear atypia. Focal intracytoplasmic pink trichohyaline granules are seen that serve to differentiate pilomatrix carcinoma from other basophilic poorly differentiated malignant tumors. ${ }^{10}$ The basaloid cells of pilomatrixoma and pilomatrix carcinoma express B-catenin. ${ }^{?}$

No epidermal connection + basaloid tumor + cuticle (small ducts) formation $=$ dermal duct tumor.

Dermal duct tumor is variant of poroma that is located largely or entirely within the dermis, where it consist of variously shaped tumor islands containing ductal lumina. Please refer to the to the previous poroma section.

No epidermal connection + basaloid tumor + focal vacuolated cytoplasm $=$ sebaceoma and sebaceous carcinoma.

Sebaceous tumors including adenoma, sebaceoma and carcinoma can be either epidermal or dermal locations. Please refer to the next sebaceous tumors discussion.

No epidermal connection + clear and/or eosino-

philic cytoplasm \pm cystic changes $=$ hidradenoma and hidradenocarcinoma

Hidradenoma is a benign adnexal neoplasm, closely related to poroma, that displays a limited degree of ductal differentiation. Histologically, it is a dermal neoplasm with a nodular, circumscribed pattern at scanning magnification.
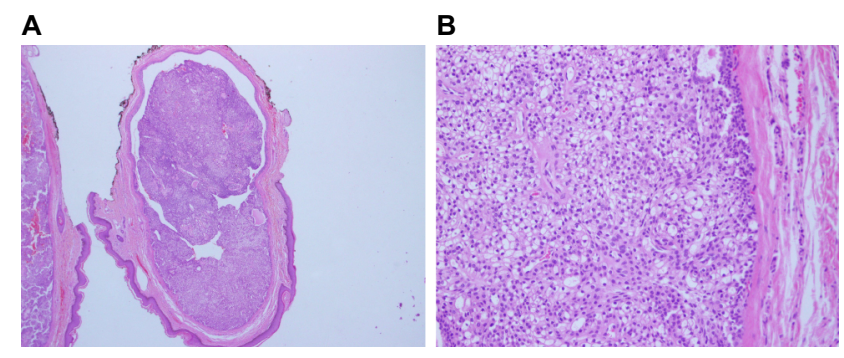

Figure 8 Dermal tumor with clear cells.

Notes: (A) Hidradenoma: well-defined dermal tumor that is disconnected from epidermis (H\&E stain original magnification $\times 40)$. (B) Hidradenoma: on a high power, eosinophilic and clear cell identified with hylanized stroma (H\&E stain original magnification $\times 200$ ).

Abbreviation: H\&E, hematoxylin and eosin.

The intervening stroma is vascularized. It is composed of two types of cells: clear and eosinophilic cells. Clear cells contain abundant glycogen, and their number varies from lesion to lesion. Eosinophilic cells are polygonal with a central vesicular nucleus. Focal cystic spaces are commonly seen (Figure 8).

No epidermal connection + ductal $/$ glandular formation $=$ syringoma, chondroid syringoma, hidradenoma papilliferum, tubular adenoma, and tubular papillary adenoma

Syringomas are small benign adnexal neoplasms that are almost always multiple. By far, the most common sites of involvement are the lower eyelids. Histologically, it is restricted to the upper reticular dermis and is composed of numerous small solid nests, cords, and tubules of epithelial cells within a dense stroma. Larger aggregates of cords and nests of cells may exhibit a "comma-like" or "tadpole-like" configuration (Figures 9A, B). In some lesions, clear cells predominate, and this pattern has been termed clear cell syringoma; it has frequently been associated with diabetes mellitus. ${ }^{8}$

Mixed tumor (chondroid syringoma) is biphasic tumor with both epithelial and stromal components. The epithelial part is composed of elongated branching tubular structures and may have follicular differentiation. Chondroid, mucoid, or fibrous stroma is usually seen (Figures 9C, D). ${ }^{8}$

Hidradenoma papilliferum is a benign neoplasm that almost always develops in the vulval and perianal regions of middle-aged women. ${ }^{11,12}$ Histologically, it is a wellcircumscribed solid or cystic dermal nodular lesion formed of frond-like papillae or tubulopapillary structures that are lined by two cell layers, inner epithelial and outer myoepithelial cell layers (Figures 9E and F). Estrogen receptors, progesterone receptors, and ARs are commonly expressed in hidradenoma papilliferum. ${ }^{13}$

Tubular adenoma (tubular papillary adenoma) is a benign neoplasm demonstrating apocrine differentiation that 
A

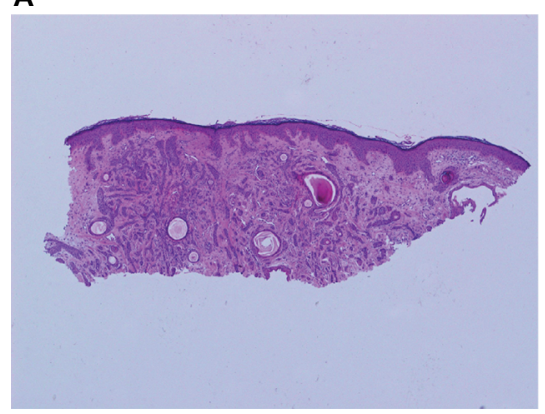

D

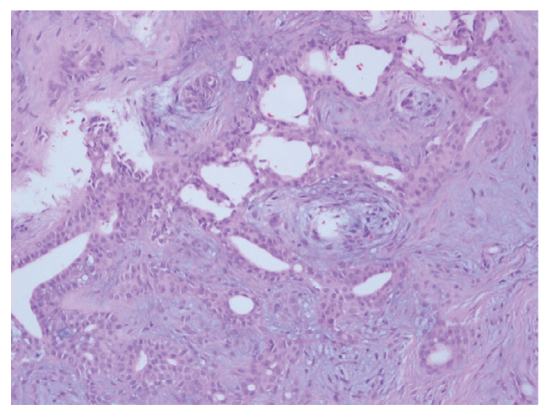

B

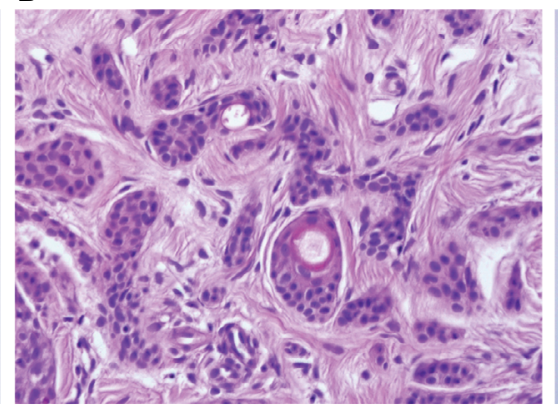

E

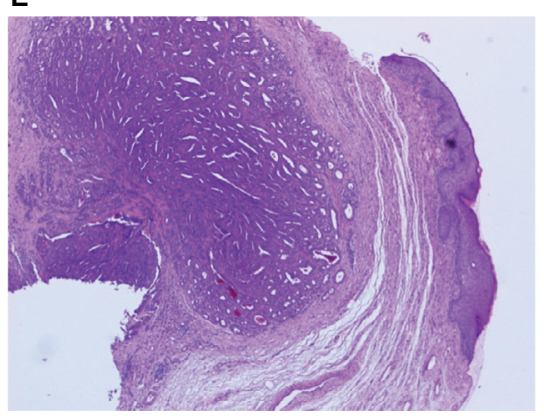

C

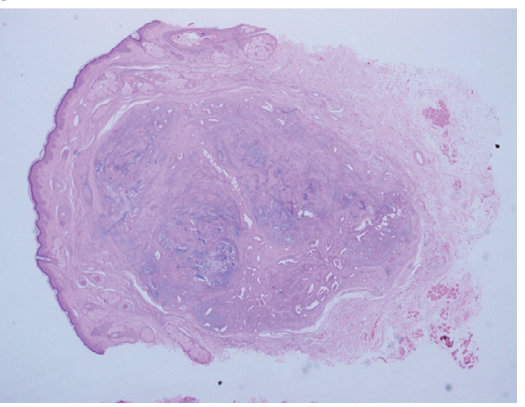

F

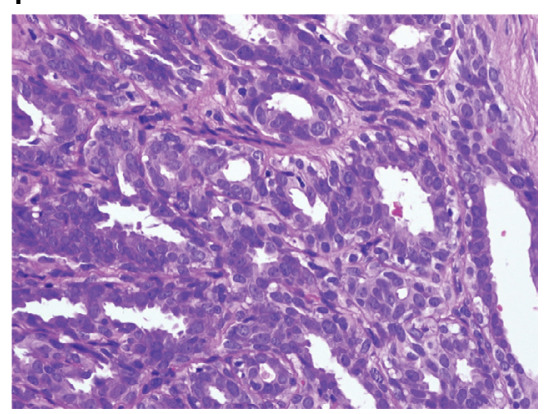

Figure 9 Dermal tumors with glandular differentiation.

Notes: (A) Syringoma: superficial, ill-defined dermal tumor with background sclerosis (H\&E stain original magnification $\times 40)$. (B) Syringoma: on a high power, the tumor is composed of small solid nests, cords, and tubules of epithelial cells within a dense stroma (H\&E stain original magnification $\times 200)$. (C) Mixed tumor (chondroid syringoma): deep, well-demarcated dermal tumor (H\&E stain original magnification $\times 20)$. (D) Mixed tumor (chondroid syringoma): on a high power, the tumor is composed of tubules, solid cords, and squamous islands embedded within a myxoid, chondroid, or fibrous stroma (H\&E stain original magnification $\times 200)$. (E) Hidradenoma papilliferum: deep, welldemarcated dermal tumor (H\&E stain original magnification $\times 20)$. (F) Hidradenoma papilliferum: on a high power, the tumor is composed of tubules with papillary formation and apocrine changes (H\&E stain original magnification $\times 200)$.

Abbreviation: H\&E, hematoxylin and eosin.

typically occurs in women on the scalp region. The tumor consists of multiple irregularly shaped tubular structures that have a double- to several-layered epithelial lining.

Many types of carcinoma with sweat gland differentiation show tubular and glandular architectures. They include microcystic adnexal carcinoma, tubular carcinoma, malignant mixed tumor, mucinous carcinoma, digital papillary carcinoma, adenoid cystic carcinoma (ACC), and apocrine carcinoma. Microcystic adnexal carcinoma is a locally infiltrative and destructive low-grade adenocarcinoma differentiated toward ducts. Histologically, it is a poorly circumscribed tumor composed of epithelial cords that invades deeply into the dermis and exhibits prominent perineural and intraneural invasion. The neoplastic cells are small, uniform and basaloid, or less commonly clear and have no or minimal cytological atypia and mitotic activity. ${ }^{1}$

Digital papillary carcinoma was historically divided histologically into aggressive digital papillary adenomas and digital adenocarcinomas. However, cases originally classified histologically as adenoma developed metastases, demonstrating that histologic parameters do not accurately predict behavior or allow distinction between adenoma and adenocarcinoma. Therefore, the term aggressive digital papillary adenoma has been abandoned in favor of classification of all such lesions as digital papillary carcinoma. It is present almost exclusively on the fingers, toes, palms, and soles. Characteristic histologic findings of this lesion include tubuloalveolar and ductal structures associated with papillary projections protruding into cystically dilated lumina. ${ }^{8}$

Mucinous carcinoma is characterized by large pools of basophilic mucin, which are compartmentalized by delicate fibrous septa, thereby creating a honeycomb pattern. Within the lakes of mucin are small "floating" islands of neoplastic epithelial cells. ${ }^{1}$

ACC is a very rare malignant tumor that is indistinguishable from its salivary gland counterpart.

\section{Tumors with sebaceous differentiation}

Sebaceous glands are outgrowths of the external root sheath of the follicle that secrete an oily substance, sebum, into the follicular space. Sebaceous differentiation is indicated by "mulberry" cells with coarsely vacuolated cytoplasm and starry nuclei. Epithelial membrane antigen (EMA) immunohistochemistry is positive in mature sebaceous cells. There are many non-sebaceous tumors that show focal sebaceous differentiation such as $\mathrm{BCC}$, trichoblastoma, and poroma (Figure 10).

Enlarged sebaceous gland size and increased number of lobule: sebaceous hyperplasia 


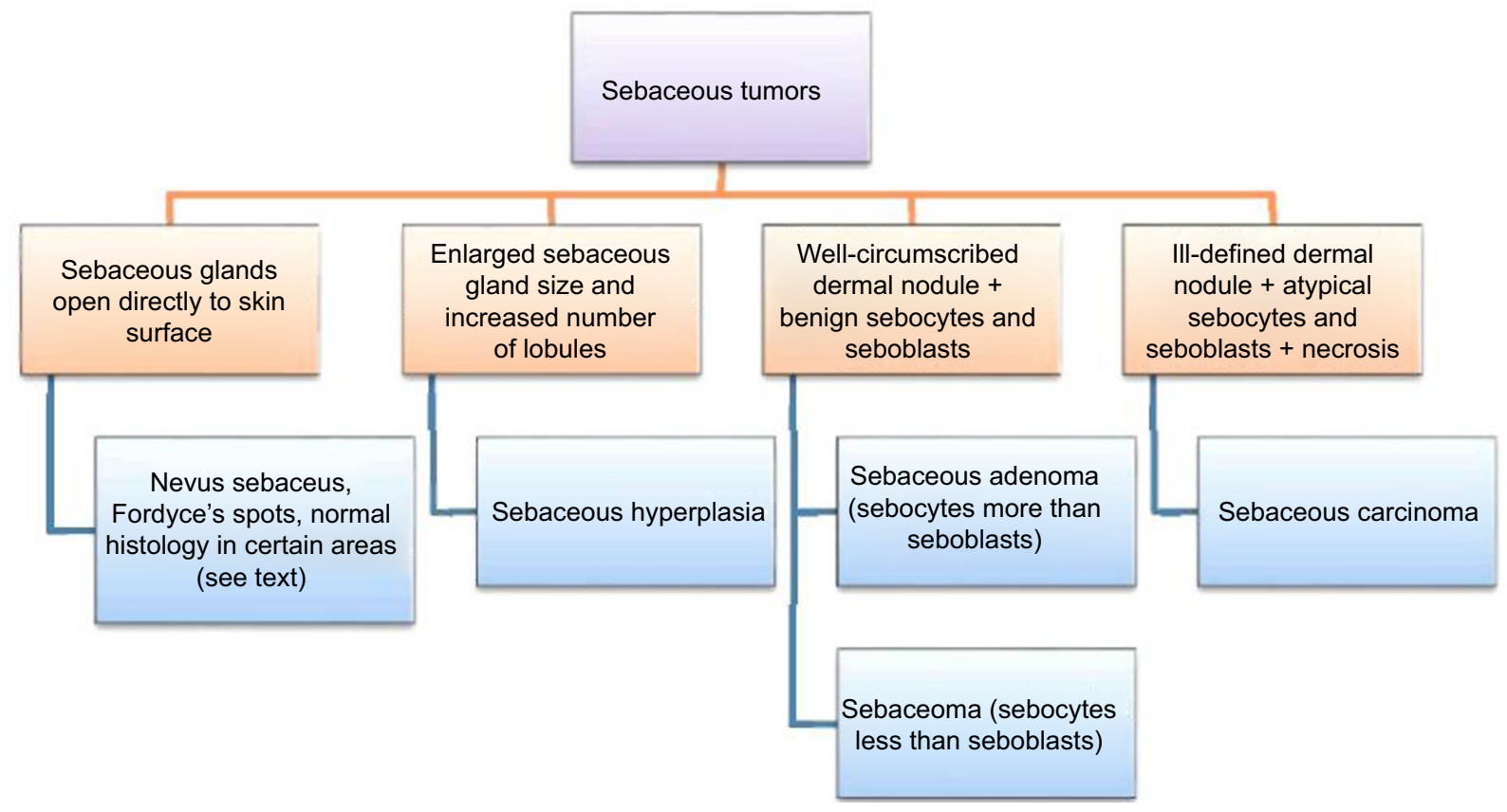

Figure 10 Approach to sebaceous tumors.

A

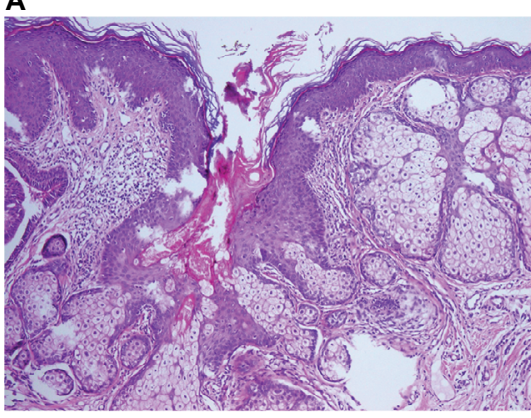

D

E
B
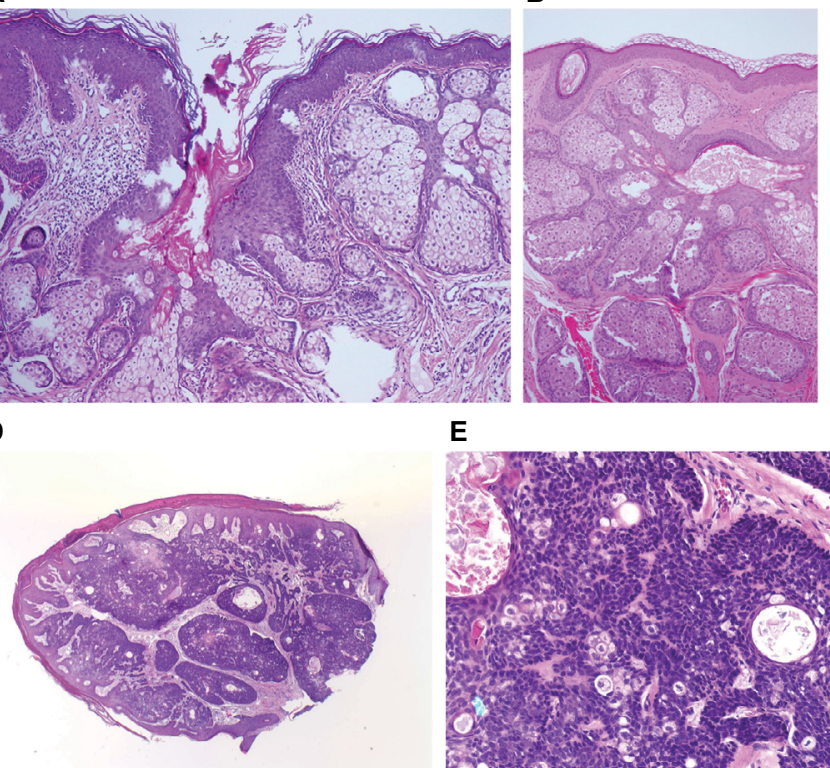

C

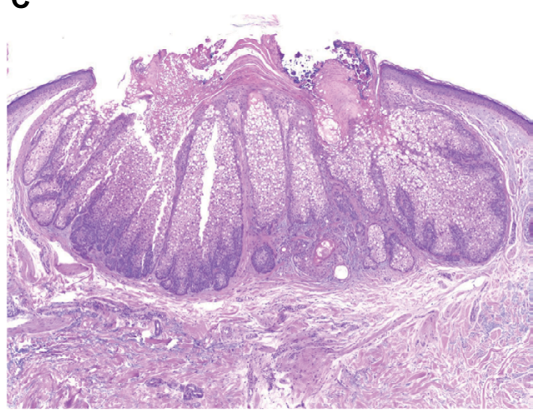

F

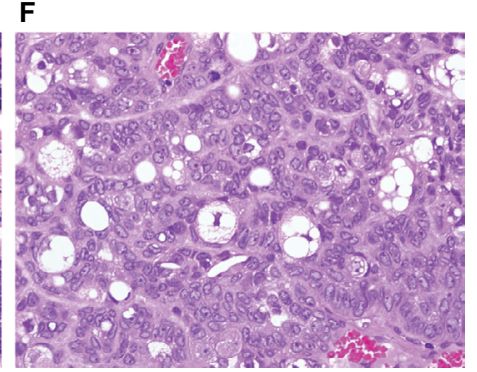

Figure I I Tumors with sebaceous differentiation.

Notes: (A) Sebaceous hyperplasia: large sebaceous gland in normal location (H\&E stain original magnification $\times 40$ ). (B) Nevus sebaceous: sebaceous gland opens directly to skin surface $(\mathrm{H} \& E$ stain original magnification $\times 40)$. (C) Sebaceous adenoma: well-defined proliferation of sebocytes (more) and seboblasts (less; H\&E stain original magnification $\times 40$ ). (D) Sebaceoma: well-defined proliferation of sebocytes (less) and seboblasts (more; H\&E stain original magnification $\times 40$ ). (E) Sebaceoma: a high power shows no nuclear atypia or necrosis (H\&E stain original magnification $\times 200)$. (F) Sebaceous carcinoma: a high power shows vacuolated cytoplasm and nuclear atypia or necrosis (H\&E stain original magnification $\times 200)$.

Abbreviation: H\&E, hematoxylin and eosin.

The lesions of sebaceous hyperplasia nearly always occur on the face. They consist of a single greatly enlarged sebaceous gland composed of numerous lobules grouped around a centrally located hair follicle (Figures 10 and 11A).
Normal sebaceous gland opens directly to skin surface: nevus sebaceous, Fordyce spots, and normal histology in certain areas 
Nevus sebaceus of Jadassohn is nearly always located on the scalp or the face as a single lesion and is present at birth. Histologically, the sebaceous glands in nevus sebaceus follow the pattern of normal sebaceous glands during infancy, childhood, and adolescence. In the first few months of life, they are well developed. During childhood, the sebaceous glands in nevus sebaceus are underdeveloped and, therefore, greatly reduced in size and number. Thus, the diagnosis of nevus sebaceus may be missed. However, the presence of incompletely differentiated hair structures is typical of nevus sebaceus. There often are cords of undifferentiated cells resembling the embryonic stage of hair follicles. At puberty, the lesion assumes its diagnostic histologic appearance. Large numbers of mature or nearly mature sebaceous glands open directly into the skin surface (Figure 11B). Ectopic apocrine glands develop in about two-thirds of the patients at puberty and sometimes at a younger age. ${ }^{14}$

Free sebaceous glands that are not associated with hair structures occur in some areas of modified skin, such as the nipple and areola of both the male and female breasts. There, they occur over the entire surface of the nipple and in Montgomery's areolar tubercles. Free sebaceous glands are found also on the labia minora and the inner aspect of the prepuce. The not-infrequent presence of free sebaceous glands on the vermilion border of the lips and on the buccal mucosa is known as Fordyce's condition. ${ }^{15}$

Well-circumscribed dermal nodule + benign sebocytes and seboblasts: sebaceous adenoma and sebaceoma

Sebaceous adenoma is present as a yellow, circumscribed nodule located on either the face or scalp. Solitary and multiple lesions have been well documented in patients with Muir-Torre syndrome. On histologic examination, it is sharply demarcated from the surrounding tissue and is composed of incompletely differentiated sebaceous lobules. Two types of cells are present in the lobules. The cells of the first type are identical to the cells representing undifferentiated basaloid cells (seboblasts). The cells of the second type are mature sebaceous cells with vacuolated cytoplasm (sebocytes) (Figure 11C). Cystic sebaceous adenomas seem to occur exclusively in patients with Muir-Torre syndrome. ${ }^{16}$ Sebaceoma is a histological variant of sebaceous adenoma, in which the basaloid epithelial cells (seboblasts) constitute $>50 \%$ of the tumor (Figures 11D, E).

Ill-defined dermal nodule + atypical sebocytes and sebo-

blasts + necrosis: sebaceous carcinoma

Sebaceous carcinomas have been traditionally classified into ocular and extraocular types. The ocular type most frequently occurs on the eyelids, where it originates from the meibomian glands and less commonly from the glands of Zeis. Extraocular sebaceous carcinoma has been reported most commonly on the head and neck. ${ }^{17}$ Histologically, sebaceous carcinoma reveals irregular lobular formations that show great variations in the size of the lobules. Although many cells are undifferentiated, distinct sebaceous cells showing a foamy cytoplasm are present in the center of most lobules. Sebaceous carcinomas of the eyelids in nearly half of the cases examined show a pagetoid spread of malignant cells in the conjunctival epithelium or the epidermis of the skin of the lid or both. ${ }^{18}$ The degree of sebaceous differentiation in sebaceous carcinoma varies greatly, as does the degree of nuclear atypicality (Figure $11 F)$. Some carcinomas display obvious sebaceous differentiation, while other examples may be composed mostly of neoplastic cells with a squamous or basaloid appearance, with sebaceous differentiation only focally apparent. EMA immunoperoxidase staining remains the best supplemental test for confirmation of sebaceous differentiation. ${ }^{7}$ Sebaceous carcinoma differs from sebaceous adenoma and sebaceoma in its asymmetry, poor circumscription, infiltrative growth pattern, and solid sheets and shows atypia and high mitotic activity.

\section{Cysts}

Cyst lined by stratified squamous epithelium + laminated keratin content: epidermal inclusion cyst $=$ infundibular cyst and milia

Dermal cysts are subdivided according to the lining epithelium and their content. The lining can be squamous, columnar or cuboidal. The cyst content is either keratin or proteinaceous material.

Epidermal inclusion cysts are slowly growing, elevated, round, firm, intradermal, or subcutaneous tumors that cease growing after having reached $1-5 \mathrm{~cm}$ in diameter. They occur most commonly on the face, scalp, neck, and trunk. Usually, a patient has only one or a few epidermal cysts and rarely many. In Gardner's syndrome, however, numerous epidermal cysts occur, especially on the scalp and face. Milia are multiple, superficially located, white, globoid, firm lesions, generally only $1-2 \mathrm{~mm}$ in diameter. Histologically, epidermal inclusion cyst and milia are lined by stratified squamous epithelium with a granular layer. The cyst is filled with keratin flakes (Figures 12 and 13A). ${ }^{8}$

Cyst lined by stratified squamous epithelium + compact keratin content: trichilemmal or pilar cysts 


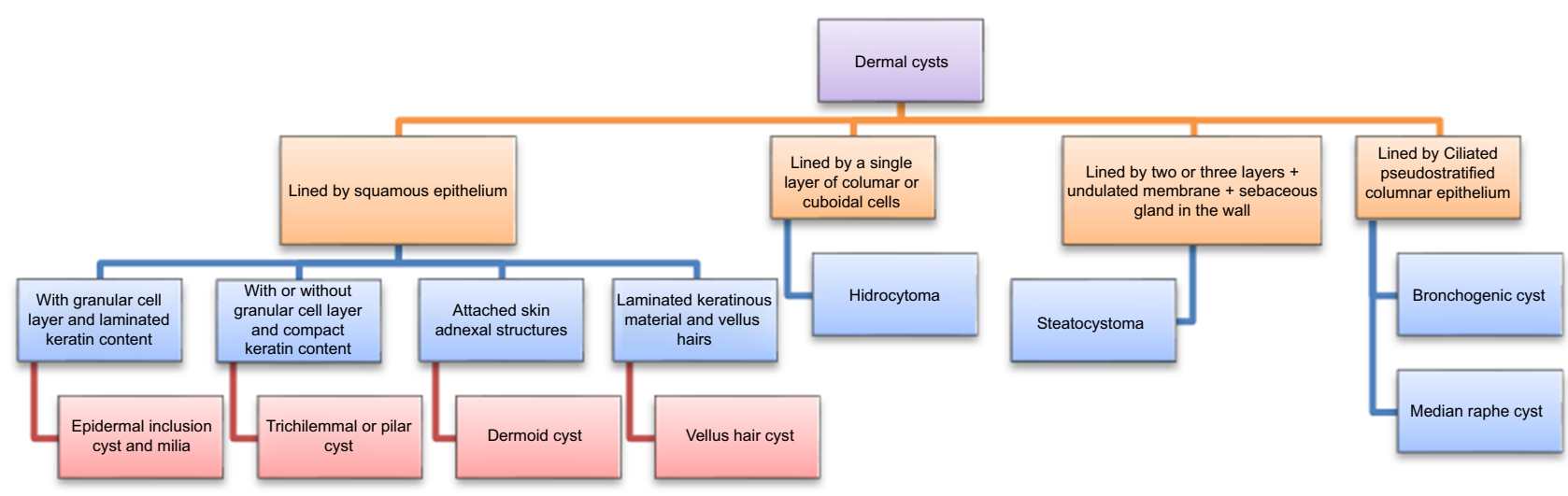

Figure 12 Approach to common dermal cysts.

A

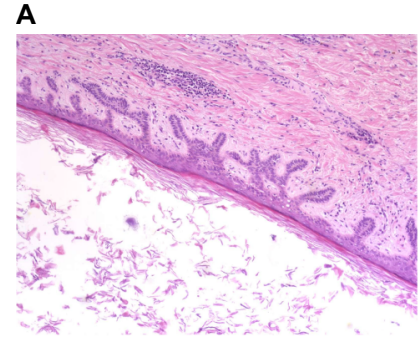

C

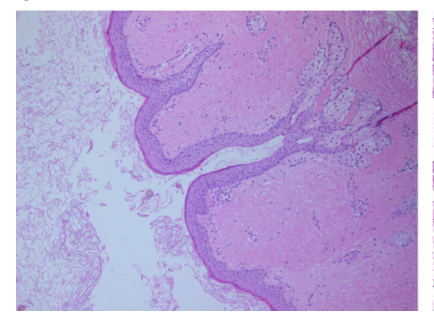

Figure 13 Dermal cysts.

Notes: (A) Epidermal inclusion cyst: lined by stratified squamous epithelium and contains lamellated keratin (H\&E stain original magnification $\times 100)$. (B) Trichilemmal cyst: lined by stratified squamous epithelium and contains compact keratin (H\&E stain original magnification $\times 100$ ). (C) Dermoid cyst: lined by stratified squamous epithelium and contains lamellated keratin with hair follicle in its wall (H\&E stain original magnification $\times 100$ ). (D) Steatocystoma: lined by squamous epithelium with sebaceous gland in its wall (H\&E stain original magnification $\times 100$ ).

Abbreviation: $\mathrm{H} \& E$, hematoxylin and eosin.

Trichilemmal cysts are lined by a squamous epithelium with no granular layer that is filled with compact keratin material (Figure 13B). ${ }^{8}$

Cyst lined by stratified squamous epithelium + attached skin adnexal structures: dermoid cyst

Dermoid cysts are subcutaneous cysts that usually are present at birth. They occur most commonly on the head, mainly around the eyes, and occasionally on the neck (Figure 13C). ${ }^{8}$

Cyst lined by squamous epithelium + laminated keratinous material and vellus hairs $=$ vellus hair cyst
In eruptive vellus hair cysts, asymptomatic follicular papules 1-2 $\mathrm{mm}$ in diameter occur (most commonly on the chest). Microscopically, it is usually seen in the mid-dermis lined by squamous epithelium. It contains laminated keratinous material and varying numbers of transversely and obliquely cut vellus hairs. ${ }^{8}$

Cyst lined by two or three layers + undulated luminal homogeneous, eosinophilic membrane + sebaceous gland in the wall: steatocystoma

Steatocystoma multiplex is inherited in an autosomal dominant pattern. One observes numerous small, rounded, moderately firm, cystic nodules that are adherent to the overlying skin and usually measure $1-3 \mathrm{~cm}$ in diameter. It appears likely that differentiation in the cyst wall of steatocystoma multiplex is to a large extent in the direction of the sebaceous $\operatorname{duct}\left(\right.$ Figure 13D). ${ }^{8}$

Cyst lined by a single layer of columnar to cuboidal cells:

hidrocystoma

Hidrocystoma is a solitary cystic nodule usually located in the lower eyelid. Histologically, cystic lesion is lined by a single layer of columnar to cuboidal cells. ${ }^{8}$

Cyst lined by ciliated pseudostratified columnar epithelium:

bronchogenic cyst

Bronchogenic cysts are rare. They are small, solitary lesions seen most commonly in the skin or subcutaneous tissue just above the sternal notch. Rarely, they are located on the anterior aspect of the neck or on the chin. As a rule, they are discovered shortly after birth. ${ }^{8}$

Cyst lined by pseudostratified columnar epithelium + located on the ventral aspect of the penis $=$ median raphe cyst 
Median raphe cysts of the penis arise usually in young adults. They are located on the ventral aspect of the penis, most commonly on the glans. The cysts are lined by pseudostratified columnar epithelium varying from one to four cells in thickness, mimicking the transitional epithelium of the urethra. ${ }^{8}$

\section{Conclusion}

In this article, we reviewed a simple diagnostic histological approach depending largely on the location of the tumor, color of the tumor in a low power, and cell architecture. Some tumors are located superficially and predominantly connect to epidermis and others lie deep in the dermis. On a low power, neoplasms can be basophilic, eosinophilic, or clear color. Architecturally, the cells arranged in tubules, papillae, or sheets.

\section{Acknowledgments}

This review does not contain any studies with human participants or animals performed by any of the author. This study has not received any funding.

\section{Disclosure}

The author reports no conflicts of interest in this work.

\section{References}

1. LeBoit PE, Burg G, Weedon D, Sarasain A, editors. World Health Organization, Classification of Tumours. Pathology and Genetics of Skin Tumours. Lyon: IARC Press; 2006.

2. Kamiya H, Oyama Z, Kitajima Y. "Apocrine" poroma: review of the literature and case report. J Cutan Pathol. 2001;28(2):101-104.
3. Brownstein MH, Mehregan AH, Bikowski JB, et al. The dermatopathology of Cowden's syndrome. Br J Dermatol. 1979;100(6):667-673.

4. Illueca C, Monteagudo C, Revert A, Llombart-Bosch A. Diagnostic value of CD34 immunostaining in desmoplastic trichilemmoma. J Cutan Pathol. 1998;25(8):435-439.

5. Welsch MJ, Krunic A, Medenica MM. Birt-Hogg-Dube syndrome. Int J Dermatol. 2005;44(8):668-673.

6. Yamamoto O, Doi Y, Hamada T, Hisaoka M, Sasaguri Y. An immunohistochemical and ultrastructural study of syringocystadenoma papilliferum. Br J Dermatol. 2002;147(5):936-945.

7. Alhumaidi A. Practical immunohistochemistry of epithelial skin tumor. Indian J Dermatol Venereol Leprol. 2012;78(6):698-708.

8. Elder DE, Elenitsas R, Johnson BL, Murphy GF. Lever's Histopathology of the Skin. 9th ed. Baltimore (MD): Lippincott Williams \& Wilkins; 2005.

9. Obaidat NA, Alsaad KO, Ghazarian D. Skin adnexal neoplasms - part 2: an approach to tumours of cutaneous sweat glands. J Clin Pathol. 2007;60(2):145-159.

10. Hardisson D, Linares MD, Cuevas-Santos J, Contreras F. Pilomatrix carcinoma: a clinicopathologic study of six cases and review of the literature. Am J Dermatopathol. 2001;23(5):394-401.

11. Loane J, Kealy WF, Mulcahy G. Perianal hidradenoma papilliferum occurring in a male: a case report. Ir J Med Sci. 1998;167(1):26-27.

12. Vang R, Cohen PR. Ectopic hidradenoma papilliferum: a case report and review of the literature. JAm Acad Dermatol. 1999;41(1):115-118.

13. Ansai S, Koseki S, Hozumi Y. An immunohistochemical study of lysosome, Cd-15 (Leu M1), and gross cystic disease fluid protein-15 in various skin tumors. Assessment of the specificity and sensitivity of markers of apocrine differentiation. Am J Dermatopathol. 1995;17(3):249-255.

14. Wilson Jones E, Heyl T. Naevus sebaceus. Br J Dermatol. 1970;82(2):99.

15. Hyman AB, Brownstein MH. Tyson's glands. Arch Dermatol. 1969;99(1):31-36.

16. Rutten A, BurgdorfW, Hugel H, et al. Cystic sebaceous tumors as marker lesions for the Muir-Torre syndrome: a histopathologic and molecular genetic study. Am J Dermatopathol. 1999;21(5):405-413.

17. Carlson JW, McGlennen RC, Gomez R, Longbella C, Carter J, Carson LF. Sebaceous carcinoma of the vulva: a case report and review of the literature. Gynecol Oncol. 1996;60(3):489-491.

18. Rao NA, Hidayat AA, McLean IW, et al. Sebaceous carcinomas of the ocular adnexa: a clinicopathologic study of 104 cases, with five-year follow-up data. Hum Pathol. 1982;13(2):113-122.
Pathology and Laboratory Medicine International

\section{Publish your work in this journal}

Pathology and Laboratory Medicine International is a peer-reviewed, open access journal focusing on innovative basic research and translational research related to pathology or human disease. The journal includes original research, updates, case reports, reviews and commentaries on current controversies. The manuscript management system is completely

\section{Dovepress}

online and includes a very quick and fair peer-review system. Visit $\mathrm{http}: / / \mathrm{www}$.dovepress.com/testimonials.php to read real quotes from published authors. 